\title{
Impact of buildings on surface solar radiation over urban Beijing
}

\author{
Bin Zhao ${ }^{1}$, Kuo-Nan Liou ${ }^{1}$, Yu Gu ${ }^{1}$, Cenlin He ${ }^{1}$, Wee-Liang Lee ${ }^{2}$, Xing Chang ${ }^{3}$, Qinbin Li $^{1}$, Shuxiao Wang ${ }^{3,4}$, \\ Hsien-Liang R. Tseng ${ }^{1}$, Lai-Yung R. Leung ${ }^{5}$, and Jiming $\mathbf{H a o}^{3,4}$ \\ ${ }^{1}$ Joint Institute for Regional Earth System Science and Engineering and Department of Atmospheric and Oceanic Sciences, \\ University of California, Los Angeles, CA 90095, USA \\ ${ }^{2}$ Research Center for Environmental Changes, Academia Sinica, Taipei, Taiwan \\ ${ }^{3}$ State Key Joint Laboratory of Environment Simulation and Pollution Control, School of Environment, Tsinghua University, \\ Beijing 100084, China \\ ${ }^{4}$ State Environmental Protection Key Laboratory of Sources and Control of Air Pollution Complex, Beijing 100084, China \\ ${ }^{5}$ Pacific Northwest National Laboratory, Richland, WA 99352, USA
}

Correspondence to: Bin Zhao (zhaob1206@gmail.com)

Received: 2 January 2016 - Published in Atmos. Chem. Phys. Discuss.: 29 January 2016

Revised: 14 April 2016 - Accepted: 1 May 2016 - Published: 12 May 2016

\begin{abstract}
The rugged surface of an urban area due to varying buildings can interact with solar beams and affect both the magnitude and spatiotemporal distribution of surface solar fluxes. Here we systematically examine the impact of buildings on downward surface solar fluxes over urban Beijing by using a 3-D radiation parameterization that accounts for 3-D building structures vs. the conventional plane-parallel scheme. We find that the resulting downward surface solar flux deviations between the 3-D and the plane-parallel schemes are generally $\pm 1-10 \mathrm{~W} \mathrm{~m}^{-2}$ at $800 \mathrm{~m}$ grid resolution and within $\pm 1 \mathrm{~W} \mathrm{~m}^{-2}$ at $4 \mathrm{~km}$ resolution. Pairs of positive-negative flux deviations on different sides of buildings are resolved at $800 \mathrm{~m}$ resolution, while they offset each other at $4 \mathrm{~km}$ resolution. Flux deviations from the unobstructed horizontal surface at $4 \mathrm{~km}$ resolution are positive around noon but negative in the early morning and late afternoon. The corresponding deviations at $800 \mathrm{~m}$ resolution, in contrast, show diurnal variations that are strongly dependent on the location of the grids relative to the buildings. Both the magnitude and spatiotemporal variations of flux deviations are largely dominated by the direct flux. Furthermore, we find that flux deviations can potentially be an order of magnitude larger by using a finer grid resolution. Atmospheric aerosols can reduce the magnitude of downward surface solar flux deviations by $10-65 \%$, while the surface albedo generally has a rather moderate impact on flux deviations. The results imply that the effect of buildings on downward surface solar fluxes may not be critically significant in mesoscale at-
\end{abstract}

mospheric models with a grid resolution of $4 \mathrm{~km}$ or coarser. However, the effect can play a crucial role in meso-urban atmospheric models as well as microscale urban dispersion models with resolutions of $1 \mathrm{~m}$ to $1 \mathrm{~km}$.

\section{Introduction}

The spatial orientation and inhomogeneous features of the earth's surface interact with direct and diffuse solar beams in an intricate manner (Liou et al., 2013). In particular, the complex and rugged surface of an urban area due to varying buildings can interact with solar beams and affect both the magnitude and spatiotemporal distribution of surface solar fluxes. The distribution of solar fluxes can significantly modulate surface heating and moistening, evapotranspiration, land-atmosphere interaction, boundary layer, and air pollutant dispersion (Lee et al., 2011; Gu et al., 2012). It is very difficult to accurately quantify the surface solar flux distribution in view of the complexity of spatial orientation and surface optical properties, especially over urban areas.

Several approaches with varying degrees of sophistication have been developed to evaluate solar fluxes at rugged surface (Dozier and Frew, 1990; Dubayah et al., 1990; Chen et al., 2006; Essery and Marks, 2007; Lai et al., 2010). Among these approaches, the 3-D Monte Carlo photon tracing approach gives the most physically representative radiative transfer calculations for an environment with complex 
3-D topography. Chen et al. (2006) and Liou et al. (2007) developed a Monte Carlo program and found that the domainaverage downward surface solar fluxes with rugged topography deviate from the unobstructed horizontal surface by $10-50 \mathrm{~W} \mathrm{~m}^{-2}$ over the Tibetan Plateau and can be as large as $600 \mathrm{~W} \mathrm{~m}^{-2}$ locally over shaded areas. The 3-D Monte Carlo approach has also been used to evaluate interactions between solar beams and other irregular surfaces, such as wind-blown sea surfaces and plant canopies (Preisendorfer and Mobley, 1986; Iwabuchi and Kobayashi, 2008; Mayer et al., 2010). However, a drawback of the 3-D Monte Carlo photon tracing approach is the enormous computational burden. To overcome this drawback, Lee et al. $(2011,2013)$ developed a parameterization of downward solar fluxes associated with topographic information based on 3-D Monte Carlo simulations. The parameterization was subsequently implemented in regional and global weather and climate models (Liou et al., 2013; Lee et al., 2015; Gu et al., 2012) in which the effects of 3-D mountainous topography on sensible and latent heat fluxes, surface hydrology, and cloud properties have been investigated and evaluated.

With the objective to improve the urban representation in land-surface schemes that has been used in numerical models, a number of urban energy balance models (or urban canopy models) have been developed, as reviewed by Grimmond et al. (2010, 2011). Some of these models have considered a building's shading effect and the reflectance of solar beams by building walls (Kusaka et al., 2001; Kusaka and Kimura, 2004; Kondo et al., 2005; Oleson et al., 2008). However, these models have at least two drawbacks. First, the 3-D radiative transfer was calculated based on simplified, evenly spaced buildings, rather than "real" buildings. Second, the diffuse, diffuse-reflected, and coupled fluxes (e.g., multiple reflections) were often oversimplified, resulting in noticeable errors due to the distinct features of the different flux components. A systematic evaluation and physical understanding of the 3-D building effect on surface solar radiation over urban areas is imperative.

In this study, we investigate the impact of buildings on downward surface solar fluxes over urban Beijing, the capital and one of the largest megacities in China. The evaluation is conducted using the 3-D radiation parameterization developed by Lee et al. (2013) coupled with the Fu-Liou-Gu (FLG) plane-parallel radiative transfer scheme (Fu and Liou, 1992; Gu et al., 2003, 2006). In Sect. 2 we describe the parameterization of 3-D topography effect on downward solar fluxes and its application over urban Beijing. In Sect. 3 we investigate the magnitude and spatiotemporal variation of deviations in downward surface solar fluxes induced by buildings and evaluate the effect of key factors by means of sensitivity simulations. Conclusions and implications are given in Sect. 4.

\section{Methodology and data source}

\subsection{Parameterization of the 3-D topography effect on downward surface solar fluxes}

In order to evaluate the impact of buildings on downward surface solar radiation, we apply the 3-D radiation parameterization over rugged surface developed by Lee et al. (2013). Below are key points of the parameterization. Note that we focus exclusively on "downward" solar fluxes in this study.

Solar radiative fluxes can be categorized into five components according to photon path: $(1)$ direct flux $\left(F_{\text {dir }}\right)$ is composed of photons hitting the ground directly from the sun without encountering scattering or reflection; (2) diffuse flux $\left(F_{\text {dif }}\right)$ contains photons experiencing single or multiple scattering by air molecules, but does not encounter surface reflection; (3) direct-reflected flux $\left(F_{\text {rdir }}\right)$ is comprised of unscattered photons reflected by nearby terrain; (4) diffusereflected flux $\left(F_{\text {rdif }}\right)$ means that photon is first scattered by air molecules and then reflected by nearby terrain; and (5) coupled flux ( $\left.F_{\text {coup }}\right)$ represents photons that after being reflected by the surface, encounter scattering and/or one or more additional surface reflections.

Conventional plane-parallel radiative transfer schemes have already been developed to calculate solar fluxes on a horizontal surface, so the purpose of the 3-D radiation parameterization is to produce relative deviations of these five flux components from those of an unobstructed horizontal surface. On the basis of 3-D Monte Carlo photon tracing simulations, Lee et al. $(2011,2013)$ utilized a multiple linear regression technique to establish the relationship between deviations in solar fluxes (response variables) and subgrid scale topographic information (independent variables). The Shuttle Radar Topography Mission (SRTM) topography data (Jarvis et al., 2008) at a resolution of $3 \operatorname{arcsec}$ (about $90 \mathrm{~m}$ ) were used to perform 3-D Monte Carlo simulations for many $10 \times 10 \mathrm{~km}^{2}$ rugged domains in the Sierra Nevada Mountain area, which were subsequently used to develop regression parameterization. Although the parameterization was developed in the Sierra Nevada area, it is applicable to other regions because it is topographic parameter-dependent rather than location-dependent. The regression equations for flux deviations in clear-sky conditions can be expressed by

$$
\left(\begin{array}{l}
F_{\text {dir }}^{\prime} \\
F_{\text {dif }}^{\prime} \\
F_{\text {rdir }}^{\prime} \\
F_{\text {rdif }}^{\prime} \\
F_{\text {coup }}^{\prime}
\end{array}\right)=\left(\begin{array}{l}
a_{1} \\
a_{2} \\
a_{3} \\
a_{4} \\
a_{5}
\end{array}\right)+\left(\begin{array}{llll}
b_{11} & b_{12} & 0 & 0 \\
b_{21} & b_{22} & 0 & b_{24} \\
0 & b_{32} & b_{33} & 0 \\
0 & b_{42} & b_{43} & 0 \\
b_{51} & b_{52} & b_{53} & 0
\end{array}\right)\left(\begin{array}{c}
\left\langle\widetilde{\mu}_{i}\right\rangle \\
\left\langle\widetilde{V}_{\mathrm{d}}\right\rangle \\
\left\langle\widetilde{C}_{\mathrm{t}}\right\rangle \\
\sigma(h)
\end{array}\right),
$$

where $F_{i}^{\prime}$ is the relative deviation of each flux component, $i=$ dir, dif, rdir, rdif, and coup. $a_{i}$ is the interception, $b_{i j}$ is the regression coefficient for a specific independent variable. $\tilde{\mu}_{i}$ is the cosine of the solar zenith angle normalized by the cosine of the slope, $\widetilde{V}_{\mathrm{d}}$ is the sky view factor normalized by the cosine of the slope, $\widetilde{C}_{\mathrm{t}}$ is the terrain configuration factor normalized by the cosine of the slope, $\sigma(h)$ is the standard 
deviation of elevation, and angle brackets denote the spatial mean of the variable within a $10 \times 10 \mathrm{~km}^{2}$ domain. Lee et al. (2013) demonstrated that the flux components predicted by these regression equations agree well with those directly calculated from Monte Carlo simulations.

\subsection{Application of the 3-D radiation parameterization to urban Beijing}

We apply the parameterization described above to Beijing, a megacity with numerous buildings, many of which are skyscrapers. Two domains with different sizes and resolutions are used (Fig. 1). Domain 1 covers urban and suburban Beijing at a grid resolution of $4 \mathrm{~km}$, which is a commonly used resolution in mesoscale atmospheric models. The Xishan mountain is located in the northwestern part of the domain, serving as a comparison of the 3-D topography effect over mountainous and urban areas. The rest of the domain is characterized by plains with typical urban landscape (e.g., buildings and roads). Domain 2 covers the urban center of Beijing at $800 \mathrm{~m}$ resolution, corresponding to the typical resolution of meso-urban models.

Following Lee et al. (2013), we use topography data at a resolution of $3 \operatorname{arcsec}$ (about $90 \mathrm{~m}$ ) from the SRTM, which provides the elevation of each $90 \mathrm{~m}$ pixel (see right panel of Fig. 1). The SRTM data mimic buildings as numerous $90 \times 90 \mathrm{~m}^{2}$ cuboids. They define the overall heights, widths, and intervals of large buildings, but can not resolve detailed geometry of buildings. Using the SRTM data, we first calculate topographical parameters (described in Sect. 2.1) for each $90 \mathrm{~m}$ pixel following the method described in Lee et al. (2011), followed by evaluating the average topographical parameters for each $4 \mathrm{~km}$ or $800 \mathrm{~m}$ grid in simulation domains. The SRTM data are for the year 2000. We note that urban development in Beijing has expanded greatly since 2000, far beyond what is represented in the SRTM data. This study aims to assess the potential magnitude of the effect of buildings on solar fluxes; the SRTM data meet the need considering that there were already numerous buildings in Beijing in 2000.

The 3-D radiation parameterization was originally developed for $10 \times 10 \mathrm{~km}^{2}$ grids. Lee et al. $(2011,2013)$ demonstrated its compatibility across various resolutions. Theoretically it is applicable to a grid resolution as fine as $800 \mathrm{~m}$ since an $800 \times 800 \mathrm{~m}^{2}$ grid encompasses a large number of $90 \mathrm{~m}$ pixels. Here we further demonstrate the compatibility associated with resolutions by comparing flux deviations in each $4 \times 4 \mathrm{~km}^{2}$ grid calculated directly from the 3-D parameterization and those from the summation of all $800 \times 800 \mathrm{~m}^{2}$ grids. We find the biases between the two are within $\pm 0.025 \mathrm{~W} \mathrm{~m}^{-2}$, indicating a reasonable compatibility between different grid resolutions. The calculation method and subsequent results are described in detail in the Supplement.
The 3-D radiation parameterization is used in conjunction with the FLG plane-parallel radiation scheme (Fu and Liou, 1992; Gu et al., 2003, 2006, 2010), which calculates solar fluxes on flat surfaces. The FLG scheme combines the delta-four-stream approximation for solar flux calculations with the delta-two/four-stream approximation for infrared flux calculations to assure both accuracy and efficiency. The solar $(0-5 \mu \mathrm{m})$ and infrared $(5-50 \mu \mathrm{m})$ spectra are divided into 6 and 12 bands, respectively, within which the correlated $k$ distribution method is used to sort gaseous absorption lines. The single-scattering properties of 18 aerosol types are parameterized by employing the Optical Properties of Aerosols and Clouds (OPAC) database.

The meteorological and chemical variables (i.e., air temperature, surface temperature, pressure, humidity, surface albedo, ozone concentrations, and aerosol optical depth) used in the FLG scheme are derived from a simulation of the Weather Research and Forecasting model (WRF, version 3.3)/Community Multi-scale Air Quality model (CMAQ, version 5.0.2). For the WRF/CMAQ simulation, we apply one-way, triple nesting domains with resolutions of 36, 12, and $4 \mathrm{~km}$, respectively (Supplement Fig. S1). We use a highresolution anthropogenic emission inventory developed by Tsinghua University for the Beijing-Tianjin-Hebei region (i.e., regions within the innermost domain) and a regional anthropogenic emission inventory for other regions in China (Zhao et al., 2013a, b; Wang et al., 2014). The WRF/CMAQ simulation used the Pleim-Xiu land surface model, in which the building effect on solar radiation is not accounted for (Pleim and Xiu, 1995). The conversion of vertically resolved aerosol mass concentrations to aerosol optical depth follows Heald (2010) and Martin and Heald (2010). The simulated meteorological parameters and concentrations of fine particles $\left(\mathrm{PM}_{2.5}\right)$ and their chemical components are in reasonable agreement with observations (Supplement Table S2, Fig. S2). The configuration of WRF/CMAQ and its evaluation against observations are described in detail in the Supplementary Material. The meteorological and chemical variables of Domain 1 (4 km resolution) are taken from the WRF/CMAQ simulation directly, while the variables in Domain 2 ( $800 \mathrm{~m}$ resolution) are assumed to be the same as their corresponding values at the $4 \mathrm{~km}$ grids.

The 3-D radiative transfer calculations are for 1 January, 1 April, 1 July, and 1 October 2012, representing four seasons. Within each day, the calculation is done every hour starting from 00:00 BT. To avoid the fluctuation of atmospheric profiles, we conduct the WRF/CMAQ simulations for 4 months (January, April, July, and October) and use monthly average meteorological and chemical variables for each of the $24 \mathrm{~h}$ in the 3-D radiative transfer calculations. For example, for the simulation of 1 January 00:00 BT, we use the average temperature at 00:00 BT of each day in January.

We conduct radiative transfer computation primarily for clear-sky conditions without aerosols, for which the 3-D radiation parameterization was developed. We also incorpo- 


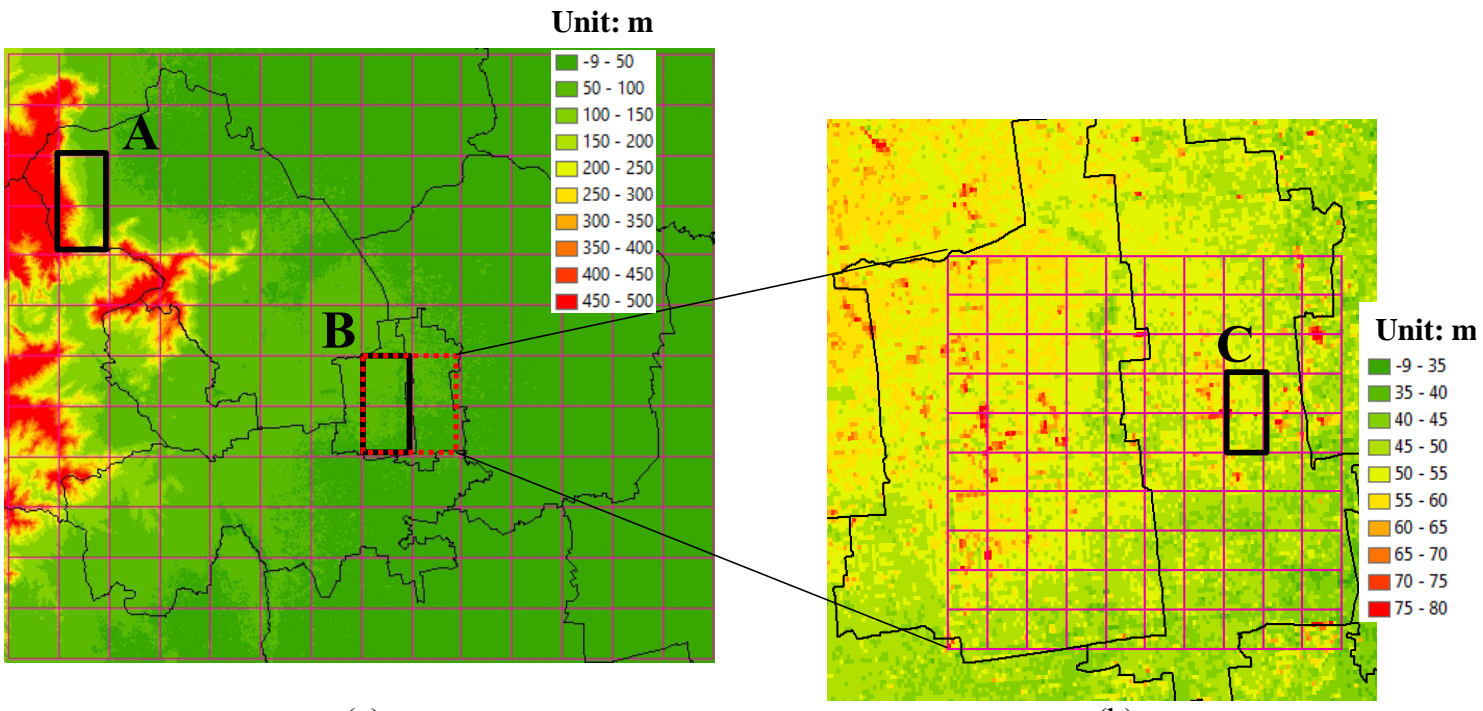

(a)

(b)

Figure 1. Modeling domains used in 3-D radiative transfer calculation: (a) Domain 1 covering urban and suburban Beijing at a grid resolution of $4 \mathrm{~km}$; (b) Domain 2 covering the urban center of Beijing at a grid resolution of $800 \mathrm{~m}$. The colors represent altitudes at a resolution of 3 arcsec (about $90 \mathrm{~m}$ ) derived from SRTM. The black thin lines represent boundaries of districts. The three black bold rectangles (defined as $\mathrm{A}, \mathrm{B}$, and $\mathrm{C}$, respectively) represent typical grids used to analyze diurnal variation and to quantify the contribution of flux components. The red dashed rectangle represents grids in Domain 1 that correspond to Domain 2.

rate aerosols for a sensitivity scenario (see Sect. 3.3.1). In the presence of aerosols, regression equations for $F_{\text {dir }}^{\prime}$ and $F_{\text {rdir }}^{\prime}$ can be directly applied because these two components do not encounter scattering. As for $F_{\text {dif }}^{\prime}, F_{\text {rdif }}^{\prime}$, and $F_{\text {coup }}^{\prime}$, the parameterization provides a first-order estimate (Lee et al., 2011, 2013). Considering that the direct flux usually dominates over other components (Chen et al., 2006; Lee et al., 2011), the parameterization is likely applicable in an environment with a large aerosol loading.

\section{Results and discussion}

\subsection{Deviations in solar fluxes from horizontal surface}

We calculate surface solar fluxes at rugged city surface by employing the 3-D radiation parameterization coupled with the FLG plane-parallel scheme. Surface solar flux deviations between the 3-D radiation parameterization and planeparallel scheme represent the effect of buildings. Figure 2 (top three rows) shows hourly flux deviations at selected times $(07: 00,12: 00$, and 17:00 BT) on 1 April in clear-sky condition without aerosols. Figure 3 depicts daily average flux deviations for four simulation days (1 January, 1 April, 1 July, and 1 October). For Domain 1 (4 km resolution), a striking feature is that deviations over urban areas are remarkably smaller than those over mountainous areas. Both hourly and daily average deviations over urban areas are generally within $\pm 1 \mathrm{~W} \mathrm{~m}^{-2}$. In contrast, hourly/daily average deviations over mountainous areas are on the order of \pm 10
$70 \mathrm{~W} \mathrm{~m}^{-2}$, except for July when daily average deviations are generally within $10 \mathrm{~W} \mathrm{~m}^{-2}$. The maximum local deviations can be up to $\pm 100 \mathrm{~W} \mathrm{~m}^{-2}$. In Domain 2 ( $800 \mathrm{~m}$ resolution), both the magnitude and the spatial pattern of deviations differ greatly from Domain 1. Flux deviations usually range between $\pm 1-10 \mathrm{~W} \mathrm{~m}^{-2}$. The magnitude of flux deviations has a significant seasonal variation associated with the position of the sun in different seasons. For example, daily average flux deviations are within $\pm 10, \pm 6$, and $\pm 1 \mathrm{~W} \mathrm{~m}^{-2}$ in January, April/October, and July, respectively. Smaller daily average deviations in July are attributable to the smaller shading effect at the north-south direction as the sun is close to its zenith at noon. In addition, the fine structure of positivenegative pairs on southern-northern or eastern-western sides of buildings is resolved in Domain 2. This phenomenon is especially pronounced when we compare flux deviations at 07:00 and 17:00 BT. Many grids show opposite-sign flux deviations at these two times, implying that they are located on the opposite side of buildings. The spatial pattern comprising of positive-negative pairs is somewhat similar to that of mountainous areas in Domain 1. By comparing Domain 1 and Domain 2, we conclude that flux deviations from the flat surface over urban areas are quite sensitive to grid resolution. The magnitude of deviations is small at a coarse resolution such as $4 \mathrm{~km}$, because of the offset of positive and negative deviations.

We further analyze the diurnal variation of flux deviations from the horizontal surface, as shown in Fig. 4. To facilitate the analysis, we select a typical mountainous area (de- 
7:00 BT, without aerosols

12:00 BT, without aerosols

17:00 BT, without aerosols

7:00 BT, with aerosols

12:00 BT, with aerosols

17:00 BT, with aerosols
Domain 1
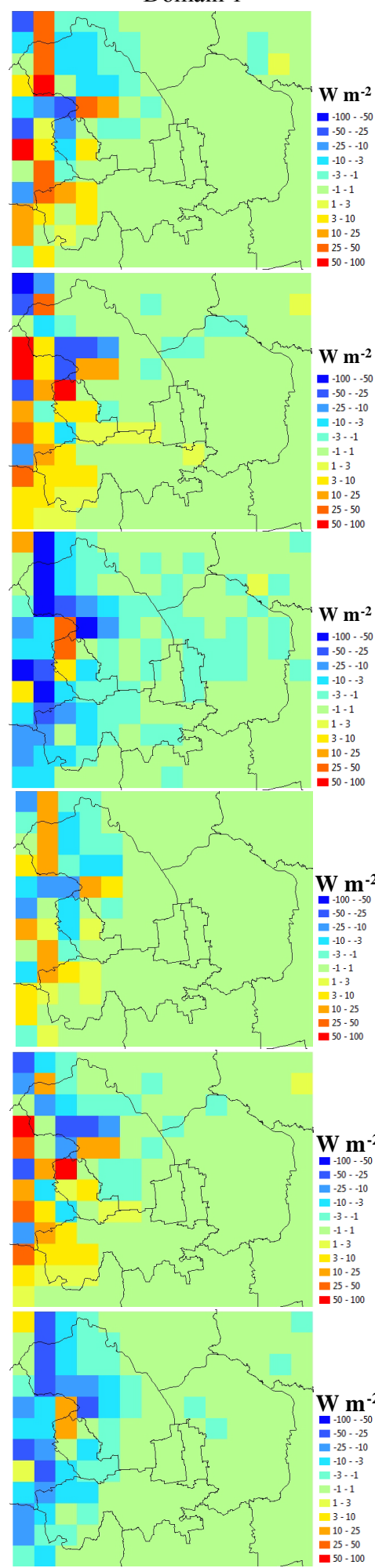

Domain 2
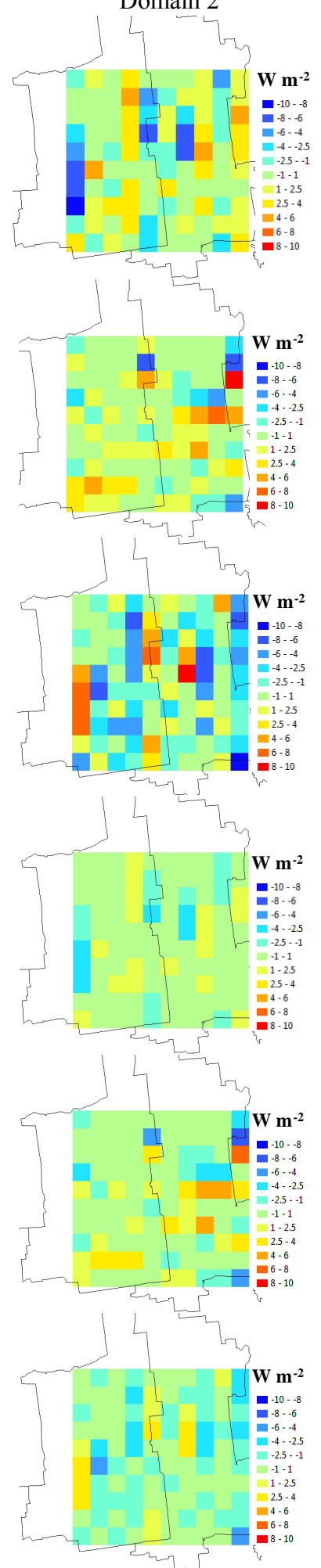

Figure 2. Surface solar flux deviations between the 3-D radiation parameterization and the plane-parallel scheme at selected times (7:00, 12:00, and 17:00 Beijing Time (BT)) on 1 April in conditions with and without aerosols. 

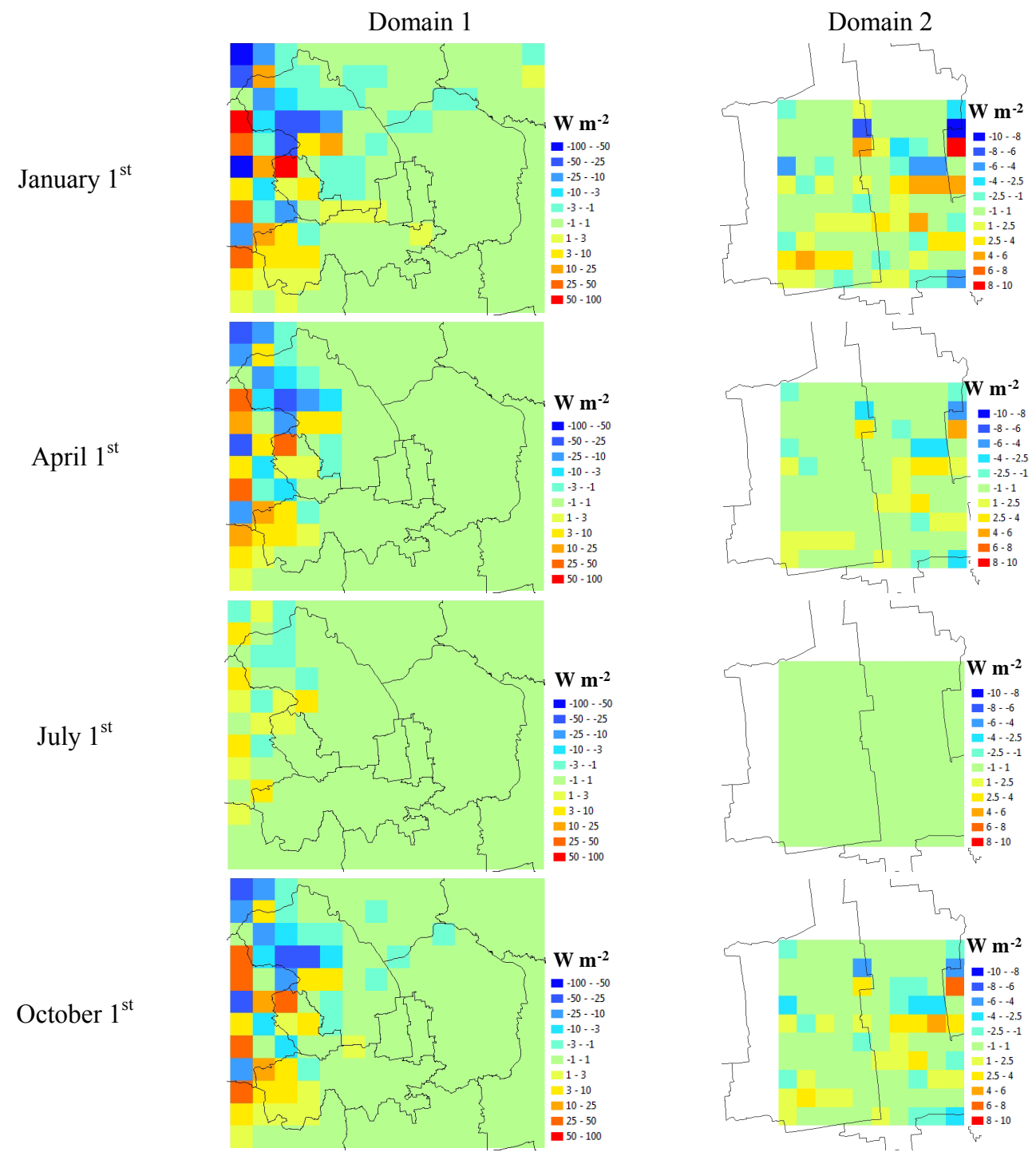

Figure 3. Daily average surface solar flux deviations between the 3-D radiation parameterization and the plane-parallel scheme in clear-sky condition without aerosols on 1 January, 1 April, 1 July, and 1 October 2012.

fined as rectangle A in Fig. 1) and a typical urban area (defined as rectangle B in Fig. 1) in Domain 1, as well as a typical urban area (defined as rectangle $\mathrm{C}$ in Fig. 1) in Domain 2. Flux deviations in the typical urban area defined in Domain 1 (Fig. 4b) are positive during 6-7 h around noon with peaks occurring at noon, while they are negative in the early morning and late afternoon. This diurnal pattern persists on all simulation days. At noon, buildings generally receive more solar energy than a flat surface due to a larger surface area facing the sun, whereas negative deviations in the early morning and late afternoon are primarily induced by larger shading areas. The diurnal pattern over the typical urban area defined in Domain 2 (Fig. 4c) substantially differs from the preceding pattern such that flux deviations are positive in the morning and negative in the afternoon. Figure 1 shows that the typical urban area defined in Domain 2 (i.e., rectangle $\mathrm{C}$ ) is mostly located on the eastern side of the buildings rather than in the western side. In this case, the eastern side faces the sun in the morning, receiving more solar fluxes than its horizontal surface counterpart. In the afternoon, the eastern side is shaded by the buildings to substantially block solar beam. We note that the diurnal variation of grids in Domain 2 is a strong function of their relative locations to the buildings. For example, the diurnal pattern is exactly opposite for a grid containing more buildings' western side. Furthermore, it is noticeable that the diurnal pattern of the typical urban area defined in Domain 2 highly resembles that of the typical mountainous area defined in Domain 1 (Fig. 4a), which is located on the eastern side of the Xishan mountain. This reveals the similarity between buildings and mountains 


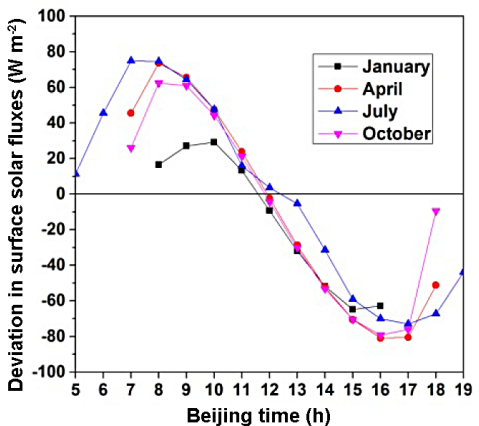

(a)

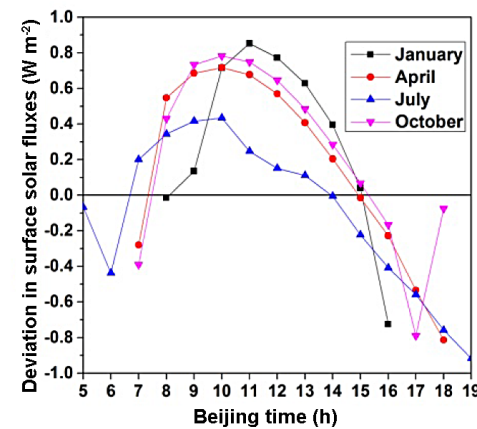

(b)

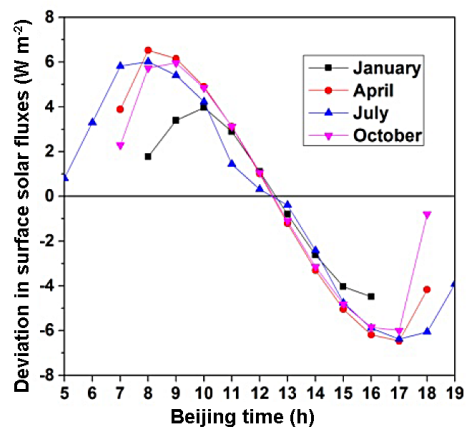

(c)

Figure 4. Diurnal variation of surface solar flux deviations between the 3-D radiation parameterization and the plane-parallel scheme in clear-sky condition without aerosols in typical grids marked by black bold rectangles in Fig. 1: (a) a typical mountainous area, defined as rectangle A; (b) a typical urban area in Domain 1, defined as rectangle B; (c) a typical urban area in Domain 2, defined as rectangle C.

in terms of their impact on surface radiation, though they are associated with different spatial scales $-4 \mathrm{~km}$ or more for mountains (Liou et al., 2013; Lee et al., 2013) and $800 \mathrm{~m}$ or less for buildings.

\subsection{Contribution of individual flux components to flux deviations}

We quantify the contribution of individual flux components to surface solar flux deviations between 3-D and planeparallel in order to gain a deeper understanding of the effect of buildings on solar flux distributions. Figure 5 shows the contribution of individual components to flux deviations on 1 April in the three typical areas defined in the last section, while Fig. S3 depicts the corresponding contributions on 4 simulation days (1 January, 1 April, 1 July, and 1 October) in the typical urban area defined in Domain 1. For the other two typical areas, only 1 April is shown because the other simulation days present very similar patterns. As described in Sect. 2.1, solar fluxes are physically categorized into five components, including direct flux, diffuse flux, direct-reflected flux, diffuse-reflected flux, and coupled flux. In Fig. 5, diffuse and coupled fluxes are merged together, considering that the coupled flux is usually negligible and that these two components are treated together in the planeparallel scheme. A striking pattern is that the direct flux largely dominates deviations from the unobstructed horizontal surface over both urban and mountainous areas. The diurnal variation of direct flux is very similar to that of the total flux, which has been illustrated in detail in the last section. In general, deviations in diffuse flux (plus coupled flux) are negative over both urban and mountainous areas since sky view factors are less than 1.0 in street canyons or valleys. Their magnitude is generally between -0.03 and $-0.10 \mathrm{~W} \mathrm{~m}^{-2}$ in typical urban areas in Domain 1 (Fig. 5b, Fig. S3) and between -0.10 and $-0.25 \mathrm{~W} \mathrm{~m}^{-2}$ in typical urban areas in Domain 2 (Fig. 5c), both peaking at noon. Deviations in directreflected and diffuse-reflected fluxes are always positive be- cause these two components do not exist on unobstructed horizontal surfaces. The magnitude of direct-reflected flux ranges between 0.01 and $0.20 \mathrm{~W} \mathrm{~m}^{-2}$ in typical urban areas (both Domain 1 and Domain 2), with peaks occurring at summer noon. Figure S3 shows that deviations in the directreflected flux can exceed those of the direct flux for a few hours around summer noon. The magnitude of the diffusereflected flux is always negligible compared with the components described above.

\subsection{Sensitivity analysis}

\subsubsection{Effect of aerosols on flux deviations}

In preceding discussions, we focused on the effect of buildings in clear-sky conditions without aerosols. Atmospheric aerosols can potentially alter the transfer of solar radiation. As described in Sect. 2.2, although the 3-D radiation parameterization was developed in clear-sky conditions without aerosols, regression equations for $F_{\text {dir }}^{\prime}$ and $F_{\text {rdir }}^{\prime}$ can be directly applied to aerosol contaminated environment, while those for $F_{\text {dif }}^{\prime}, F_{\text {rdif }}^{\prime}$, and $F_{\text {coup }}^{\prime}$ can provide a first-order estimate. Figure 2 shows hourly flux deviations between 3-D and plane-parallel at selected times (07:00, 12:00, and 17:00 BT) on 1 April with and without aerosols. The results on the other simulation days (1 January, 1 July, and 1 October) are quite similar, and thus are not shown. In general, the inclusion of aerosols reduces the magnitude of surface flux deviations without changing the spatial pattern. This can be explained by the attenuation of total solar fluxes by aerosols across the domain. Over the urban center (Domain 2), aerosols reduce the magnitude of daily average deviations by about $15-$ $30 \%$. The reduction ratios are significantly higher in the early morning and late afternoon (40-65\%) than at noon (10-25\%), mainly due to higher aerosol optical depths in the early morning/late afternoon. In this study, interactions between buildings and aerosols are not considered in the simulation. For example, photons reflected by buildings can be 


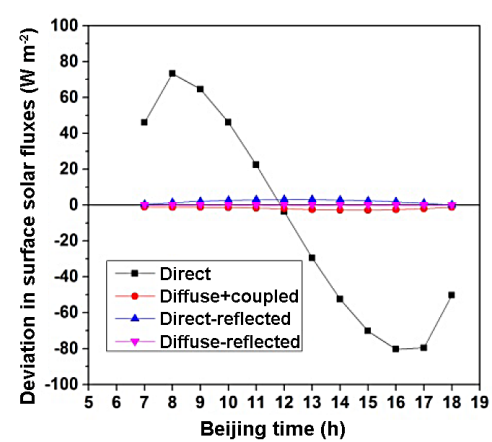

(a)

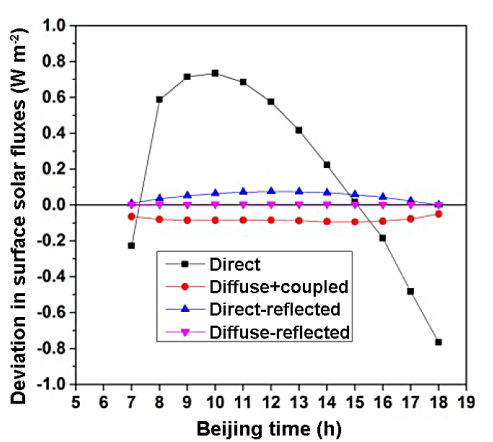

(b)

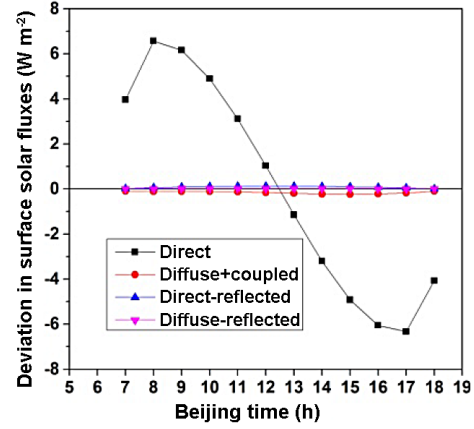

(c)

Figure 5. Contributions of individual components to surface solar flux deviations between the 3-D radiation parameterization and the planeparallel scheme in clear-sky condition without aerosols in typical grids on 1 April. Panel (a), (b), and (c) are for the same grids as Fig. $4 a$, b, and c.

further scattered/absorbed by aerosols, and vice versa. Given that diffuse-reflected and coupled fluxes are much smaller than direct flux, the resulting errors should be minor. The 3D Monte Carlo photon tracing program is needed in order to achieve a more accurate evaluation of the effect of aerosols on flux deviations.

\subsection{Sensitivity of flux deviations to spatial resolutions}

As demonstrated in Sect. 3.1, the magnitude of flux deviations from the flat surface is quite sensitive to spatial resolutions. Over urban areas, hourly deviations are $\pm 1-10 \mathrm{~W} \mathrm{~m}^{-2}$ at $800 \mathrm{~m}$ resolution and within $\pm 1 \mathrm{~W} \mathrm{~m}^{-2}$ at $4 \mathrm{~km}$ resolution. The smaller values in coarser grids can be explained by the compensation effect of positive and negative deviations on the opposite side of buildings. Judging from the right panel of Fig. 1, an $800 \times 800 \mathrm{~m}^{2}$ grid still covers quite a few buildings, which motivates us to explore the potential effect of buildings at even finer resolutions. As a test case, we present a rough estimate of flux deviations at a 3 arcsec (about $90 \mathrm{~m}$ ) resolution (shown in Fig. 6) by applying the 3D radiation parameterization to 3 arcsec topography data derived from SRTM. Theoretically, the parameterization may not be applicable to a spatial resolution less than about $1 \mathrm{~km}$ with good accuracy (Lee et al., 2013). The reason is that the radiation parameterization is developed based on gridaverage topographic parameters, so it is valid only if a model grid comprises a number of topographic pixels (Lee et al., 2011, 2013). Nevertheless, it suffices to provide an initial estimate for flux deviations, though results must be interpreted with care. Of course, a more accurate estimation should be made using the Monte Carlo method in future studies. Figure 6 shows that hourly deviations in $90 \mathrm{~m}$ grids are generally between $\pm 5-50 \mathrm{~W} \mathrm{~m}^{-2}$, and the maximum local deviations can reach about $\pm 100 \mathrm{~W} \mathrm{~m}^{-2}$. This is notably higher than flux deviations at $800 \mathrm{~m}$ resolution. These results highlight the potential importance of 3-D building effects on the mi- croscale modeling with resolutions of 1-100 m (e.g., urban dispersion models), which requires further studies.

\subsubsection{Sensitivity of flux deviations to the surface albedo}

The surface albedo used in the 3-D radiation parameterization was directly derived from WRF/CMAQ simulation results, which ranges between 0.15 and 0.20 and represents the typical surface albedo of urban areas. However, there is a wide variety of roofing materials with distinct albedos (Prado and Ferreira, 2005). One geoengineering proposal to ameliorate the effect of urban heat island was to use reflective roofing material or to paint existing roofs white (Jacobson and Ten Hoeve, 2012). There are also increasing numbers of buildings with glass surfaces. To evaluate the potential effect of amplified surface albedo on flux deviations from the horizontal surface, we design three sensitivity cases in which domain-wide surface albedo was uniformly increased to $0.35,0.50$, and 0.65 . Figure 7 shows simulated surface solar flux deviations in a typical urban area in Domain 1 (defined as rectangle B in Fig. 1) as a function of surface albedo. We focus on urban areas in Domain 1 (4 km resolution) because it is the region where the largest relative contribution of the reflected flux is identified (see Fig. 5), implying a potentially large sensitivity to surface albedo. Figure 7 shows a moderate impact of surface albedo on flux deviations during the day. The largest sensitivity occurs at summer noon, at which a large albedo of 0.65 can amplify flux deviations from $0.1-0.4 \mathrm{~W} \mathrm{~m}^{-2}$ to about $0.6 \mathrm{~W} \mathrm{~m}^{-2}$. Compared with the case of a $4 \mathrm{~km}$ resolution, the change in surface albedo results in a much smaller relative change in flux deviations at $800 \mathrm{~m}$ resolution, because the relative contribution of the reflected flux is smaller at $800 \mathrm{~m}$ resolution (see Fig. 5).

\subsection{Implications for atmospheric studies}

The present results have important implications for future studies. Deviations in surface solar fluxes are within $1 \mathrm{~W} \mathrm{~m}^{-2}$ 


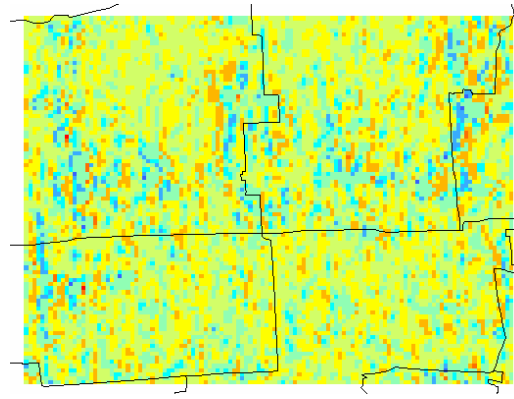

(a)

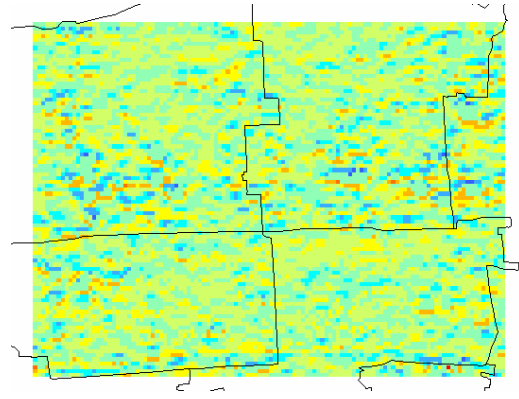

(b)

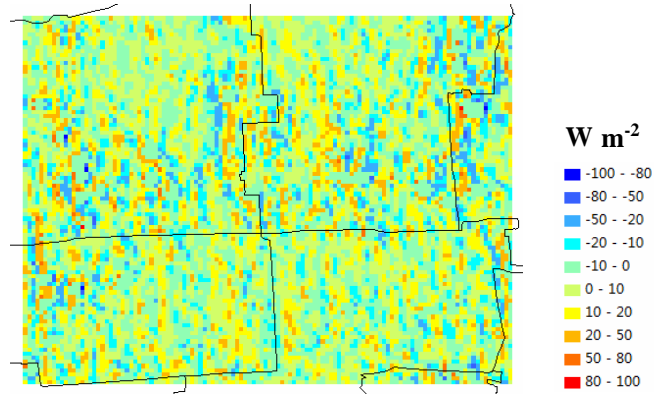

(c)

Figure 6. Surface solar flux deviations between the 3-D radiation parameterization and the plane-parallel scheme on 1 April at a grid resolution of $3 \mathrm{arcsec}$ (about $90 \mathrm{~m}$ ). (a) 07:00 BT; (b) 12:00 BT; (c) 17:00 BT. The size of the simulation domain is the same as Domain 2 defined in Fig. 1. An elevation map at a $90 \mathrm{~m}$ resolution for the simulation domain is also shown in the right panel of Fig. 1.

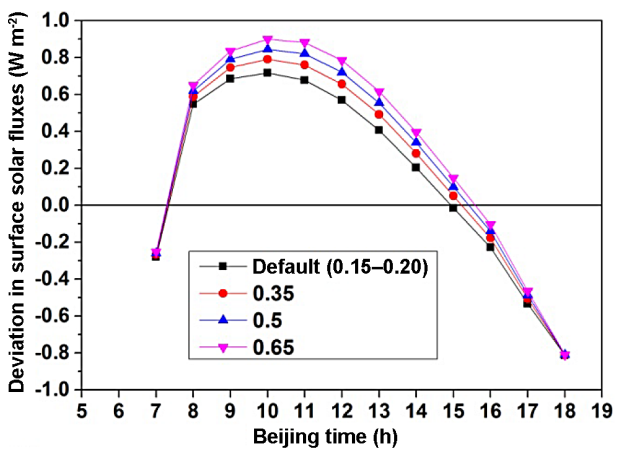

(a)

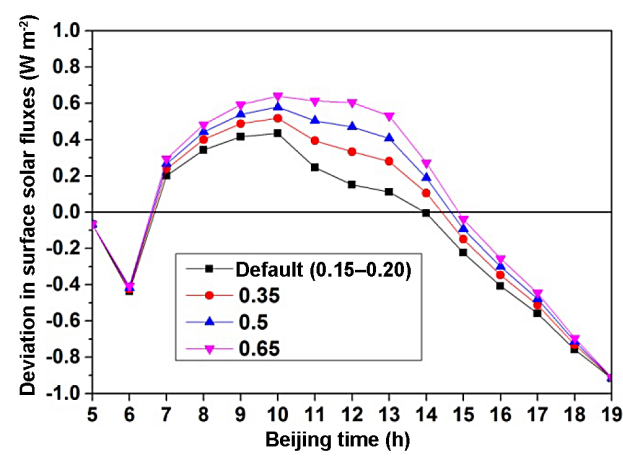

(b)

Figure 7. Sensitivity of surface solar flux deviations between the 3-D radiation parameterization and the plane-parallel scheme to the surface albedo in a typical urban area in Domain 1 (defined as rectangle B in Fig. 1) on (a) 1 April, (b) 1 July.

at a $4 \mathrm{~km}$ or coarser resolution due to the offset of positive and negative flux deviations, therefore the effect of buildings may not be critically significant in mesoscale atmospheric models. Nevertheless, the effect can not be neglected if there is a substantially inhomogeneous subgrid-scale distribution of plants, accumulated snow, and building/road materials, etc.; in this case, subgrid-scale flux deviations may result in biased evapotranspiration, snowmelting, and heat fluxes, etc. For meso-urban models with a typical resolution of about $1 \mathrm{~km}$ (e.g., urbanized MM5 model, uMM5; Taha et al., 2008), the 3-D building effects become quite significant (about $\pm 1-10 \mathrm{~W} \mathrm{~m}^{-2}$ ). The parameterization used in this study can be readily incorporated in these models to account for 3-D building effects. As for computational fluid dynamics models (e.g., FLUENT) and urban dispersion models (e.g., Atmospheric Dispersion Modelling System, ADMS) with resolutions of $1-100 \mathrm{~m}$, this study implies that flux deviations induced by buildings might be up to $\pm 100 \mathrm{~W} \mathrm{~m}^{-2}$. The large flux deviations can significantly alter local energy balance, and thus affect the spatial distribution of temperature and small-scale flows around buildings and/or through street canyons. Therefore, the 3-D building effects on solar fluxes can play a crucial role in numerical simulation of urban meteorology and air pollutant dispersion. The present 3-D radiation parameterization may not be applicable to $1-100 \mathrm{~m}$ resolutions. As such, a more physically based approach directly using an appropriate 3-D Monte Carlo photon tracing program will be needed to account for 3-D building effects more precisely. Also, topography data such as the recently released SRTM data sets at a resolution of 1 arcsec (about $30 \mathrm{~m}$ ) may also be useful for the study of 3-D building effects.

\section{Conclusions}

In this study, we systematically evaluated the impact of buildings on surface solar fluxes over urban Beijing using the 3-D radiation parameterization developed in our previous study in connection with the FLG radiative transfer scheme. The evaluation was conducted in two simulation domains with grid resolutions of $4 \mathrm{~km}$ and $800 \mathrm{~m}$, representing typical resolutions for mesoscale and meso-urban models, respectively.

Over urban Beijing, deviations in surface solar fluxes between the 3-D radiation parameterization and the plane- 
parallel scheme are generally $\pm 1-10 \mathrm{~W} \mathrm{~m}^{-2}$ at $800 \mathrm{~m}$ resolution and within $\pm 1 \mathrm{~W} \mathrm{~m}^{-2}$ at $4 \mathrm{~km}$ resolution. Pairs of positive-negative flux deviations on different sides of buildings are resolved at $800 \mathrm{~m}$ resolution, while they offset each other at $4 \mathrm{~km}$ resolution. Deviations in surface solar fluxes over urban areas are considerably smaller than those over mountainous areas using preceding grid resolutions.

Flux deviations over urban areas are positive around noon but negative in the early morning and late afternoon at $4 \mathrm{~km}$ resolution. The corresponding deviations at $800 \mathrm{~m}$ resolution, in contrast, show diurnal variations that are strongly dependent on the grids' relative locations to buildings. Both the magnitude and spatiotemporal variations of flux deviations are largely dominated by the direct flux.

With a series of sensitivity simulations, we show that atmospheric aerosols reduce the magnitude of surface flux deviations by $10-65 \%$ without changing the spatial pattern. Simulated deviations in surface fluxes are very sensitive to spatial resolution. They can potentially reach up to $\pm 100 \mathrm{~W} \mathrm{~m}^{-2}$ at a high resolution of about $90 \mathrm{~m}$. The surface albedo has a moderate impact on flux deviations during the day, while the impact can be substantial at summer noon.

This study implies that the effect of buildings on surface solar fluxes may not be critically important in mesoscale atmospheric models ( $\geq 4 \mathrm{~km}$ resolution). However, the effect can play a crucial role in meso-urban atmospheric models as well as microscale urban dispersion models with resolutions of $1 \mathrm{~m}$ to $1 \mathrm{~km}$.

Besides the 3-D radiation parameterization, the urban canopy models (Chen et al., 2011; Grimmond et al., 2010; Kusaka and Kimura, 2004; Martilli et al., 2002) have been frequently used in urban climate simulations to consider the building effect on solar radiation. These two models investigate the radiative effect of buildings with different methods. Below we provide a brief discussion of the differences between these two models, and their advantages and limitations. We recommend future studies be done to systematically compare these two models, and to improve current simulation of building effect on solar radiation.

The present 3-D radiation parameterization was developed on the basis of a 3-D Monte Carlo photon tracing approach. We parameterize the downward surface solar fluxes using the grid-average topographic information to reproduce the results in order to reduce the computational burden of 3-D Monte Carlo photon tracing calculations. In urban canopy models, the radiative transfer equation was established by employing simplified, evenly spaced buildings. Then, the average building geometry parameters (e.g., building height, building width, street width, etc.) are calculated for each model grid and subsequently used in radiative transfer calculation (Chen et al., 2011; Grimmond et al., 2010; Kusaka and Kimura, 2004; Martilli et al., 2002).

The present 3-D radiation parameterization and the commonly used urban canopy models both have their advantages and limitations. The 3-D radiation parameterization directly relates surface solar fluxes to "real" (rather than simplified) topographic data, resulting in the realistic spatiotemporal distribution of solar fluxes. In addition, the 3-D radiation parameterization treats individual flux components (i.e., the direct, diffuse, direct-reflected, diffuse-reflected, and coupled fluxes) separately taking into account the distinct feature of different flux components. However, the diffuse, diffusereflected, and coupled fluxes are usually oversimplified in urban canopy models (e.g. isotropic radiation is assumed).

The 3-D radiation parameterization also has several limitations. First, the urban topography data used in the 3-D radiation simulation cannot resolve the detailed geometry of buildings, which could introduce uncertainty in evaluating the building effect on solar fluxes. The grid resolutions used in our 3-D radiation simulation $(4 \mathrm{~km}$ and $800 \mathrm{~m})$ are considerably larger than most buildings. We found that positive and negative flux deviations on different sides of buildings often offset each other within a model grid. For this reason, the detailed geometry of buildings produces relatively minor effects on simulated solar fluxes. The effects could be much larger if we would use a grid resolution comparable to the dimension of most buildings. Future studies should be done to quantify the impact of detailed building geometry on surface solar fluxes. Second, while urban canopy models often partition total fluxes at roof, wall, and road to facilitate computations of the energy exchange at building domain, it is difficult to do similar partitioning in the 3-D radiation parameterization since complex building geometrical parameters are not resolved in the 3-D radiation parameterization.

\section{The Supplement related to this article is available online at doi:10.5194/acp-16-5841-2016-supplement.}

Acknowledgements. This research was supported by the NSF under grant AGS-0946315 and AGS-1523296. LRL was supported by Department of Energy Office of Science Biological and Environmental Research through the Regional and Global Climate Modeling program. PNNL is operated for DOE by Battelle Memorial Institute under contract DE-AC05-76RL01830.

Edited by: Q. Fu

\section{References}

Chen, F., Kusaka, H., Bornstein, R., Ching, J., Grimmond, C., Grossman-Clarke, S., Loridan, T., Manning, K. W., Martilli, A., Shiguang, M., Sailor, D., Salamanca, F. P., Taha, H., Tewari, M., Xuemei, W., Wyszogrodzki, A. A., and Chaolin, Z.: The integrated wrf/urban modelling system: Development, evaluation, and applications to urban environmental problems, Int. J. Climatol., 31, 273-288, doi:10.1002/joc.2158, 2011. 
Chen, Y., Hall, A., and Liou, K. N.: Application of threedimensional solar radiative transfer to mountains, J. Geophys. Res.-Atmos., 111, D21111, doi:10.1029/2006jd007163, 2006.

Dozier, J. and Frew, J.: Rapid calculation of terrain parameters for radiation modeling from digital elevation data, IEEE T. Geosci. Remote, 28, 963-969, doi:10.1109/36.58986, 1990.

Dubayah, R., Dozier, J., and Davis, F. W.: Topographic distribution of clear-sky radiation over the konza prairie, kansas, Water Resour. Res., 26, 679-690, doi:10.1029/89wr03107, 1990.

Essery, R. and Marks, D.: Scaling and parametrization of clearsky solar radiation over complex topography, J. Geophys. Res.Atmos., 112, D10122, doi:10.1029/2006jd007650, 2007.

$\mathrm{Fu}, \mathrm{Q}$. and Liou, K. N.: On the correlated k-distribution method for radiative-transfer in nonhomogeneous atmospheres, J. Atmos. Sci., 49, 2139-2156, doi:10.1175/15200469(1992)049<2139:Otcdmf>2.0.Co;2, 1992.

Grimmond, C. S. B., Blackett, M., Best, M. J., Barlow, J., Baik, J. J., Belcher, S. E., Bohnenstengel, S. I., Calmet, I., Chen, F., Dandou, A., Fortuniak, K., Gouvea, M. L., Hamdi, R., Hendry, M., Kawai, T., Kawamoto, Y., Kondo, H., Krayenhoff, E. S., Lee, S. H., Loridan, T., Martilli, A., Masson, V., Miao, S., Oleson, K., Pigeon, G., Porson, A., Ryu, Y. H., Salamanca, F., ShashuaBar, L., Steeneveld, G. J., Tombrou, M., Voogt, J., Young, D., and Zhang, N.: The international urban energy balance models comparison project: First results from phase 1, J. Appl. Meteorol. Clim., 49, 1268-1292, doi:10.1175/2010JAMC2354.1, 2010.

Grimmond, C. S. B., Blackett, M., Best, M. J., Baik, J. J., Belcher, S. E., Beringer, J., Bohnenstengel, S. I., Calmet, I., Chen, F., Coutts, A., Dandou, A., Fortuniak, K., Gouvea, M. L., Hamdi, R., Hendry, M., Kanda, M., Kawai, T., Kawamoto, Y., Kondo, H., Krayenhoff, E. S., Lee, S. H., Loridan, T., Martilli, A., Masson, V., Miao, S., Oleson, K., Ooka, R., Pigeon, G., Porson, A., Ryu, Y. H., Salamanca, F., Steeneveld, G. J., Tombrou, M., Voogt, J. A., Young, D. T., and Zhang, N.: Initial results from phase 2 of the international urban energy balance model comparison, Int. J. Climatol., 31, 244-272, doi:10.1002/joc.2227, 2011.

Gu, Y., Farrara, J., Liou, K. N., and Mechoso, C. R.: Parameterization of cloud-radiation processes in the ucla general circulation model, J. Climate, 16, 3357-3370, doi:10.1175/15200442(2003)016<3357:Pocpit>2.0.Co;2, 2003.

Gu, Y., Liou, K. N., Xue, Y., Mechoso, C. R., Li, W., and Luo, Y.: Climatic effects of different aerosol types in china simulated by the ucla general circulation model, J. Geophys. Res.-Atmos., 111, D15201, doi:10.1029/2005jd006312, 2006.

Gu, Y., Liou, K. N., Chen, W., and Liou, H.: Direct climate effect of black carbon in china and its impact on dust storms, J. Geophys. Res.-Atmos., 115, D00K14, doi:10.1029/2009JD013427, 2010.

Gu, Y., Liou, K. N., Lee, W.-L., and Leung, L. R.: Simulating 3-D radiative transfer effects over the Sierra Nevada Mountains using WRF, Atmos. Chem. Phys., 12, 9965-9976, doi:10.5194/acp-129965-2012, 2012.

Heald, C. L.: Geos-chem aerosol optics, available at: http://www.atmos.colostate.edu/ heald/docs/GEOS_Chem_ optics_description.pdf (last access: 11 May 2016), 2010.

Iwabuchi, H. and Kobayashi, H.: Modeling of radiative transfer in cloudy atmospheres and plant canopies using monte carlo methods, Frcgc technical report 8, 2008.
Jacobson, M. Z. and Ten Hoeve, J. E.: Effects of urban surfaces and white roofs on global and regional climate, J. Climate, 25, 1028-1044, doi:10.1175/Jcli-D-11-00032.1, 2012.

Jarvis, A., Reuter, H. I., Nelson, A., and Guevara, E.: Hole-filled seamless srtm data v4, available at: http://srtm.Csi.Cgiar.Org (last access: 30 December 2015), International Centre for Tropical Agriculture, 2008.

Kondo, H., Genchi, Y., Kikegawa, Y., Ohashi, Y., Yoshikado, H., and Komiyama, H.: Development of a multi-layer urban canopy model for the analysis of energy consumption in a big city: Structure of the urban canopy model and its basic performance, Bound.-Lay. Meteorol., 116, 395-421, doi:10.1007/s10546-0050905-5, 2005.

Kusaka, H. and Kimura, F.: Coupling a single-layer urban canopy model with a simple atmospheric model: Impact on urban heat island simulation for an idealized case, J. Meteorol. Soc. Jpn., 82, 67-80, doi:10.2151/Jmsj.82.67, 2004.

Kusaka, H., Kondo, H., Kikegawa, Y., and Kimura, F.: A simple single-layer urban canopy model for atmospheric models: Comparison with multi-layer and slab models, Bound.-Lay. Meteorol., 101, 329-358, doi:10.1023/A:1019207923078, 2001.

Lai, Y. J., Chou, M. D., and Lin, P. H.: Parameterization of topographic effect on surface solar radiation, J. Geophys. Res.Atmos., 115, D01104, doi:10.1029/2009jd012305, 2010.

Lee, W. L., Liou, K. N., and Hall, A.: Parameterization of solar fluxes over mountain surfaces for application to climate models, J. Geophys. Res.-Atmos., 116, D01101, doi:10.1029/2010jd014722, 2011.

Lee, W. L., Liou, K. N., and Wang, C. C.: Impact of 3-d topography on surface radiation budget over the tibetan plateau, Theor. Appl Climatol., 113, 95-103, doi:10.1007/s00704-012-0767-y, 2013.

Lee, W.-L., Gu, Y., Liou, K. N., Leung, L. R., and Hsu, H.-H.: A global model simulation for 3-D radiative transfer impact on surface hydrology over the Sierra Nevada and Rocky Mountains, Atmos. Chem. Phys., 15, 5405-5413, doi:10.5194/acp-15-54052015, 2015.

Liou, K. N., Lee, W. L., and Hall, A.: Radiative transfer in mountains: Application to the tibetan plateau, Geophys. Res. Lett., 34, L23809, doi:10.1029/2007g1031762, 2007.

Liou, K. N., Gu, Y., Leung, L. R., Lee, W. L., and Fovell, R. G.: A WRF simulation of the impact of 3-D radiative transfer on surface hydrology over the Rocky Mountains and Sierra Nevada, Atmos. Chem. Phys., 13, 11709-11721, doi:10.5194/acp-1311709-2013, 2013.

Martilli, A., Clappier, A., and Rotach, M. W.: An urban surface exchange parameterisation for mesoscale models, Bound.-Lay. Meteorol., 104, 261-304, doi:10.1023/a:1016099921195, 2002.

Martin, R. and Heald, C. L.: Aerosol optical properties update for geos-chem v8-03-01, available at: http://wiki.seas.harvard. edu/geos-chem/index.php/Aerosol_optical_properties (last access: 11 May 2016), 2010.

Mayer, B., Hoch, S. W., and Whiteman, C. D.: Validating the MYSTIC three-dimensional radiative transfer model with observations from the complex topography of Arizona's Meteor Crater, Atmos. Chem. Phys., 10, 8685-8696, doi:10.5194/acp-10-86852010, 2010.

Oleson, K. W., Bonan, G. B., Feddema, J., Vertenstein, M., and Grimmond, C. S. B.: An urban parameterization for a global climate model. Part i: Formulation and evaluation 
for two cities, J. Appl. Meteorol. Clim., 47, 1038-1060, doi:10.1175/2007JAMC1597.1, 2008.

Pleim, J. E. and Xiu, A.: Development and testing of a surface flux and planetary boundary layer model for application in mesoscale models, J. Appl. Meteorol., 34, 16-32, 1995.

Prado, R. T. A. and Ferreira, F. L.: Measurement of albedo and analysis of its influence the surface temperature of building roof materials, Energ. Buildings, 37, 295-300, doi:10.1016/j.enbuild.2004.03.009, 2005.

Preisendorfer, R. W. and Mobley, C. D.: Albedos and glitter patterns of a wind-roughened sea-surface, J. Phys. Oceanogr., 16, 1293-1316, doi:10.1175/15200485(1986)016<1293:Aagpoa>2.0.Co;2, 1986.

Taha, H.: Episodic performance and sensitivity of the urbanized MM5 (uMM5) to perturbations in surface properties in Houston Texas, Bound.-Lay. Meteorol., 127, 193-218, doi:10.1007/s10546-007-9258-6, 2008.
Wang, S. X., Zhao, B., Cai, S. Y., Klimont, Z., Nielsen, C. P., Morikawa, T., Woo, J. H., Kim, Y., Fu, X., Xu, J. Y., Hao, J. M., and He, K. B.: Emission trends and mitigation options for air pollutants in East Asia, Atmos. Chem. Phys., 14, 6571-6603, doi:10.5194/acp-14-6571-2014, 2014.

Zhao, B., Wang, S. X., Wang, J. D., Fu, J. S., Liu, T. H., Xu, J. Y., $\mathrm{Fu}, \mathrm{X}$., and Hao, J. M.: Impact of national nox and $\mathrm{SO}_{2}$ control policies on particulate matter pollution in china, Atmos. Environ., 77, 453-463, doi:10.1016/j.atmosenv.2013.05.012, 2013a.

Zhao, B., Wang, S. X., Liu, H., Xu, J. Y., Fu, K., Klimont, Z., Hao, J. M., He, K. B., Cofala, J., and Amann, M.: NOx emissions in China: historical trends and future perspectives, Atmos. Chem. Phys., 13, 9869-9897, doi:10.5194/acp-13-9869-2013, 2013 b. 